\title{
Metallurgical assessments on 316L stainless steel thin walled plate fabricated through GMAW based typical Wire Arc Additive Manufacturing
}

\author{
${ }^{a}$ M.Sowrirajan, ${ }^{b}$ S.Vijayan, ${ }^{c}$ M.Arulraj and d J.Sundaresan \\ ${ }^{a, d}$ Department of Mechanical Engineering, Coimbatore Institute of Engineering and \\ Technology, Tamilnadu, India \\ ${ }^{b}$ Department of Mechanical Engineering National Institute of Technology, Tiruchirappalli, \\ Tamilnadu \\ ${ }^{c}$ Department of Mechanical Engineering, Sri Krishna Polytechnic College, Coimbatore \\ ***Corresponding Author:sowrirajanmechanical@gmail.com
}

\begin{abstract}
Wire Arc Additive Manufacturing (WAAM) is developing trendy process for the fabrication of metal components nowadays. In the present study, the concept of WAAM is employed but typical concept is used for fabricating a thin walled plate sample using AISI 316L grade of stainless steel. The plate size is limited for ease up to laying only three weld beads in traverse direction rather than vertically as in the case of additive manufacturing. The chemical composition of fabricated sample is analysed for checking the use of WAAM for metal component fabrication. The ferrite number is also found and reported for supporting the fabricated component to withstand the corrosion. The low carbon steel was used as a parent metal to deposit the fabricating stainless steel thin plate. Microstructure of interface between base metal and fabricating metal is also revealed for confirming defect free component fabrication. These results are found to be satisfactory enough and thus the WAAM shall be used for the fabrication of desired components also especially in stainless steels.
\end{abstract}

\section{Key words}

WAAM, stainless steel, thin walled component, chemical composition, ferrite number, Microstructure

\section{Introduction}

Wire Arc Additive Manufacturing (WAAM) is a welding based Additive Manufacturing found to be a trendy way for the manufacturing of metal components by both fabrication industries as well as research organizations. As this is new developing process, a lot more to be addressed and proved by researchers for making this process to be accepted worldwide for the manufacturing of metal components [1]. To support this point, many of the research organizations have already started working and publishing their results for the development of this WAAM process. Though, many have been working in the WAAM component fabrication research, to name a few Cranfield University, University of Nottingham, UK and University of Wollongang, Australia and various institutes in India including Indian Institute 
of Technology Kanpur, Indian Institute of Technology Madras, National Institute of Technology Trichy, Coimbatore Institute of Engineering and Technology, Coimbatore etc. have achieved their best possible outcome in the fabrication of metallic components by various welding processes.

Normally in arc-welding based WAAM, metal component is made by depositing weld beads over another as layer by layer whereas an another typical method of fabrication could be followed when especially the height of the metal component to be fabricated would fall well within the weld thickness of single weld deposition height. As a case, a thin walled plate could be considered, but the thickness could be achieved with single deposition itself but multiple depositions are required to covered the required length and breadth of the thin plate to be fabricated. This can be noticed as illustrated in Fig. 1. Thus, a typical method of welding based fabrication is carried out in this work to demonstrate the feasibility of fabrication of thin walled metal plates.

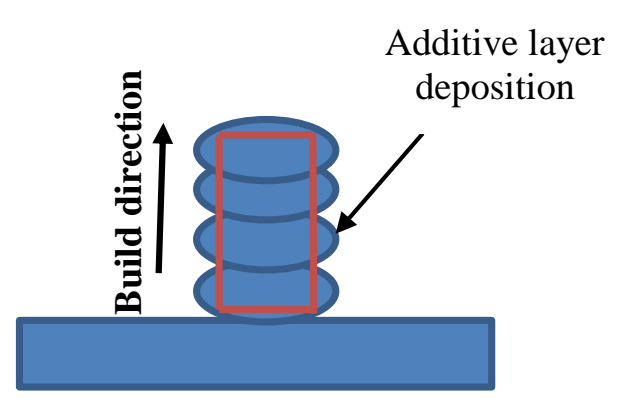

(a) Usual AM

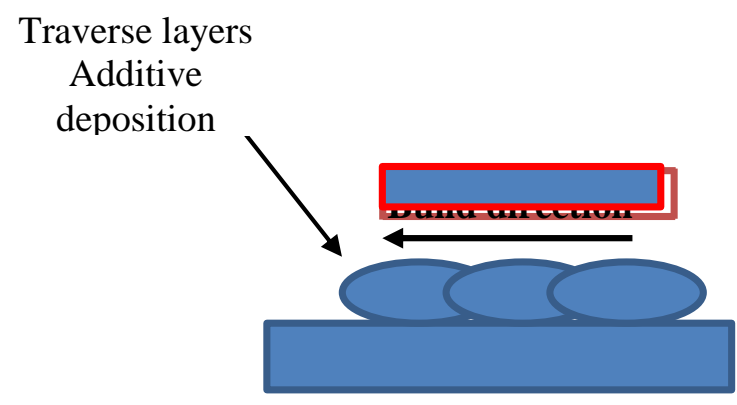

(b) Typical AM

Fig. 1 Illustration of typical WAAM process

Thin walled plates are made in order to meet many of the requirements in industries. Usually, those plates are fabricated using different manufacturing methods. Various welding processes include Gas Metal Arc Welding (GMAW), Gas Tungsten Arc Welding (GTAW), Shielded Metal Arc Welding (SMAW), Plasma Arc Welding (PAW), Submerged Arc Welding (SAW), Flux Cored Arc Welding (FCAW) and laser welding etc. and are impressive processes more frequently engaged for WAAM process among fabrication industries as well researchers [1,2]. Nowadays WAAM is a developing process for the fabrication of industry ready components. Actually, WAAM uses automation with welding heat source to melt the metal and to deposit the metal into required shape of the component being fabricated by adding the layer by layer depositions. WAAM is represented in Fig 1 for understanding [3]. In the present work the thin plate is attempted to be fabricated by depositing additive weld beads not exactly in z-direction but in $\mathrm{x}$-direction to add weld beads in traverse direction to obtain thin plate lengthy sample.

On the other hand, Stainless steel is a broad term metal that denotes to iron-based alloys containing chromium. Generally, numerous types of stainless steel are readily available in engineering world [4]. Normally, the percentage of chromium, molybdenum, nickel, and 
other alloying elements is the key factor in distinguishing between kinds of stainless steel grades. All the grades of stainless steel are convened within five main groups. They are austenitic, precipitation-hardened, ferritic, martensitic and duplex [5]. WAAM is a variant AM process used for the fabrication of components [6]. But accurate analysis of the chemical composition of a material is required because the quality of the component fabricated using this WAAM mainly depends upon the chemical composition throughout the fabricated components [7]. Because there is a possibility of difference in compositions along the weld metals as the entire component is to be fabricated by depositing layer by layer in different more weld passes. Therefore, it is strongly mandatory to verify the compositions between the fabricated metal layers. Chemical composition analysis may require the concentrations of the mechanisms in a sample. An active ingredient that reports an exclusive performance to the product being manufactured should be determined in order to understand the components performance or quality.

Moreover, ferrite content while the fabrication of component using any grades of stainless steel is a paramount important. The phase balance is also significant since it controls the entire properties of the alloy component fabricated. In fact the ferrite phase reports the strength of producing component and the austenite phase imparts toughness, corrosion resistance [8]. However, welding for the manufacture of components may alter the phase balance by amounts, depending on the different welding parameters selected [9], and so it is also important to measure the ferrite content of weld zones. An accurate evaluation contributes for the product life-span prediction, avoiding premature failures or unscheduled stops. In the case of austenitic stainless steels, a value from 2 to $5 \%$ of ferrite content in the weld bead is not only acceptable [10], but also expected to ensure a higher resistance to stress corrosion cracks and reducing the risk of solidification cracking. Different techniques of microstructural characterization are commonly applied to evaluate the ferrite content in stainless steel, such as optical microscopy, scanning electron microscopy, X-ray diffraction, metallographic replication, vibrating sample magnetometer, and the ferritoscope etc [11]. Among the listed techniques, it is reasonable to emphasize the ferritoscope as the most appropriate technique for the ferrite content evaluation in industrial environment, because besides its portability, the equipment is simple to operate and provides a direct nondestructive response for different types of stainless steels $[12,13]$. Also, it is well recognized that solidification behaviour in the fusion zone controls the size and shapeof grain structure of the fabricating component and the dispersal of weld inclusions and some weld defects such as porosity and hot cracks. Meanwhile the component properties and integrity of the weld metal rest on on the solidification behaviour and the resulting microstructure, consideration of weld pool solidification behaviour through microstructural evaluation of interface is essential [14].

In the present study, austenitic stainless steel of grade $316 \mathrm{~L}$ is employed for fabricating thin plate component using welding as a trial to real time fabrication. A typical GMAW welding process is used in this study for the fabrication of thin plate sample. Usually in WAAM the weld beads are deposited layer over the layer but the deposition of weld bead with overlapping is exercised in the present study especially for producing thin walled component samples with laying beads in traverse direction. Actually this method would 
ensure the repeatable ability of the WAAM process with essential qualities. The fabricated sample was then employed for the chemical composition analysis in order to verify the nature ability of WAAM for building such components. The overlapping zone was analysed with much care considering the repeating metal melted during welding. Also, the ferrite content in the fabricated samples was measured with help of Ferritscope for ensuring the standards required for stainless steel fabrication. These results were very satisfactory and the thin walled plate sample fabricated is found to be a reliable one. Microstructure of the interface between base plate and deposited metal for the fabrication of thin walled plate is also revealed and found satisfactory quality welds during the fabrication. Therefore, WAAM is identified as one of the key method for the fabrication of thin walled plate components in future.

\section{Materials and methods}

The material used in the present study and the details of thin plate fabrication using GMAW welding, chemical compositions details and ferrite content measurement details are furnished in this section as discussed in the further sections.

\subsection{Parent and Filler Material used}

Low carbon high tensile structural steel (ASTM A 105 / IS: 2062) was used as the base material for welding based fabrication. Austenitic stainless steel (AISI 316L grade) was selected as filler material in the present study to fabricate thin walled plate samples on structural steel plates. It is available in the form of filler wire at the market especially for the GMAW process in different diameters. The 316L stainless steel filler wire of $1.2 \mathrm{~mm}$ diameter was used to pursue this research work [15]. The austenitic stainless steels containing carbon content of less than $0.03 \%$ not only reduces sensitization in weld deposits but increases ferrite content by restricting the carbon content to a maximum of $0.03 \%$ [16]. Hence, these steels render sufficient immunity to carbide precipitation in the sensitizing temperature range of $425^{\circ} \mathrm{C}$ to $870^{\circ} \mathrm{C}$ so that components being fabricated would enhance their lifetime of service. The chemical composition of the filler metal used is shown in Table 1 .

Table 1 Chemical composition of filler wire metal used

\begin{tabular}{|l|l|l|l|l|l|l|}
\hline Material & $\mathrm{C}$ & $\mathrm{Si}$ & $\mathrm{Mn}$ & $\mathrm{Cr}$ & $\mathrm{Ni}$ & $\mathrm{Mo}$ \\
\hline $\begin{array}{l}\text { Filler metal } \\
\text { wire (316L) }\end{array}$ & 0.03 & 0.65 & 0.45 & 8.47 & 2.20 & 0.75 \\
\hline
\end{tabular}

\subsection{Thin walled plate samples fabrication by GMAW}

The experiments for fabricating thin walled plate sample was conducted using Ador make GMAW machine available at Welding Research Laboratory, Coimbatore Institute of Engineering Technology, Coimbatore, India. The experimental setup contains a welding manipulator that could control the welding process as well. The experimental setup of gas metal arc welding used for the present work is shown in Figure 2. The prepared structural 
steel low carbon base plate was pre-processed using grinding and cleaning processes to enable metal joining. The filler wire was fed with the help of wire feeder. There were three numbers of weld beads were deposited as additive layer depositions in traverse direction since the size of the fabricating plate is designed so for making thin walled plate component. An effective value of $40 \%$ bead overlapping was maintained [17]. The fabricated sample was permitted to cool naturally between every passes to reduce heat affected zone (HAZ) and the inter-pass temperature is maintained within the suitable level to avoid warping. The thin walled plate sample fabricated details are given in Figure 3.

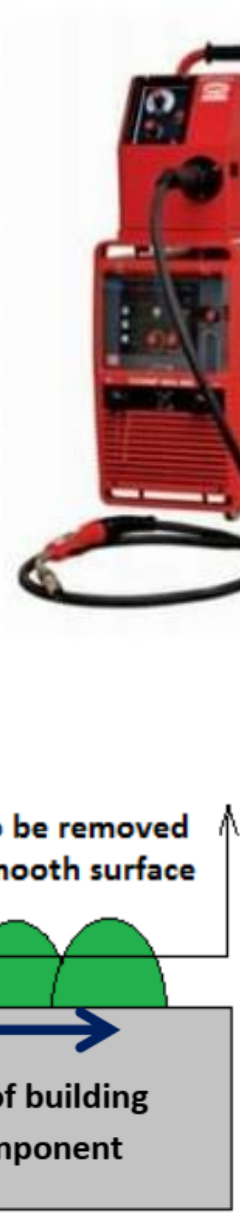

(a)

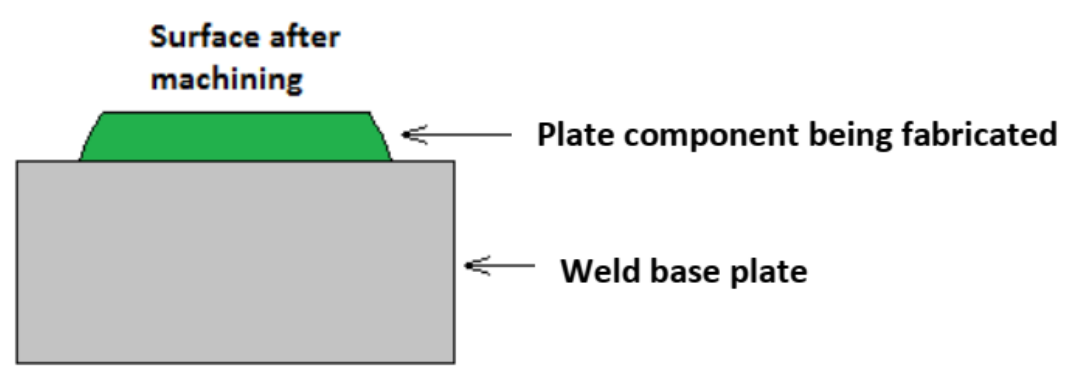

(b)

Fig. 3 Component fabrication (a) Weld beads (b) Thin walled plate component after weld deposits

\subsection{Analysing the chemical composition}

The chemical composition of fabricated thin plate sample was determined using optical emission spectrometer. The top surface of sample processed as flat is taken for study and three burns at different locations of the sample were prepared to investigate the chemical composition. Figure 4 shows the locations of chemical composition study conducted on fabricated sample. The average of the three readings was calculated and the same is considered for further discussion [18]. 


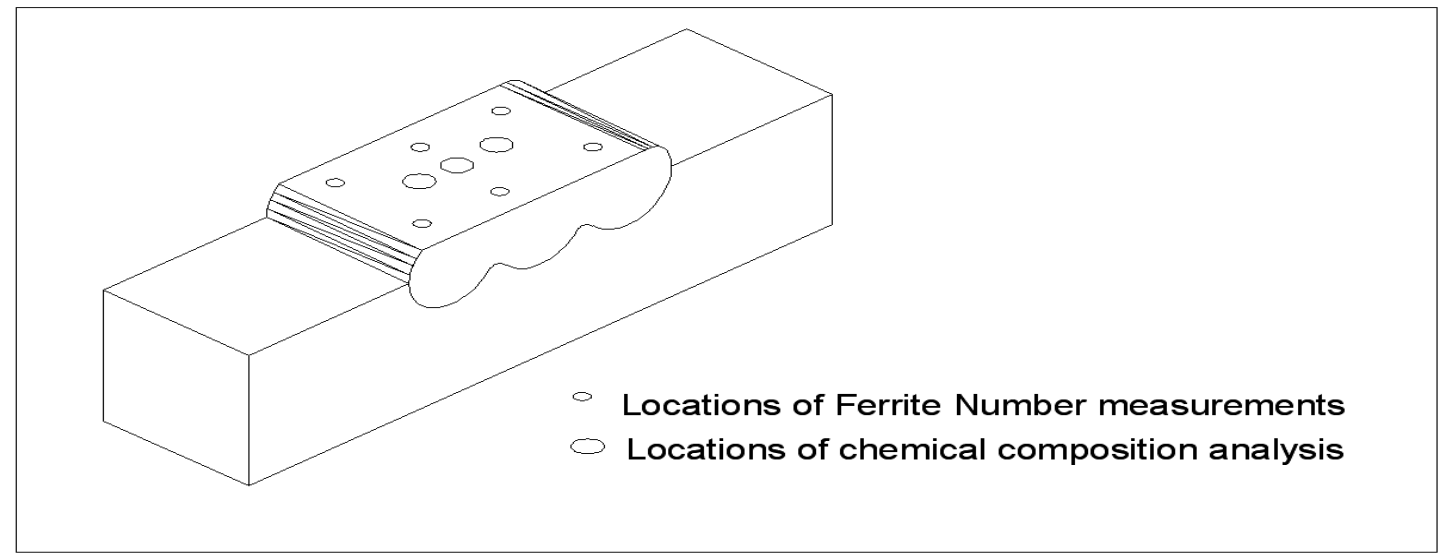

Fig. 4 Locations of chemical composition analysis and Ferrite Number measurement

\subsection{Measurement of ferrite content}

Stainless steel is frequently the material of the first choice for many applications where it deals with high temperatures and pressures. The concluding ferrite content in stainless steel after fabricating the component regulates the properties such as strength, corrosion resistance toughness and phase stability etc. If the ferrite content in the fabricated component is too low, then stainless steel processing places e.g. welding may crack at elevated temperature. If the ferrite content is very high, then the welded places may come to be weaker and susceptible to corrosion. The austenitic stainless steel deposit containing less than $0.03 \%$ carbon content not only reduces the sensitization in bead depositions but normally increases ferrite content. By maintaining the carbon content to a maximum of $0.03 \%$, steels offer adequate immunity to carbide precipitation in the sensitizing temperature range of $425^{\circ} \mathrm{C}$ to $870^{\circ} \mathrm{C}$ [19]. Therefore, the steels can be safely welded and even stress relieved if necessary without compromising its corrosion resistance.

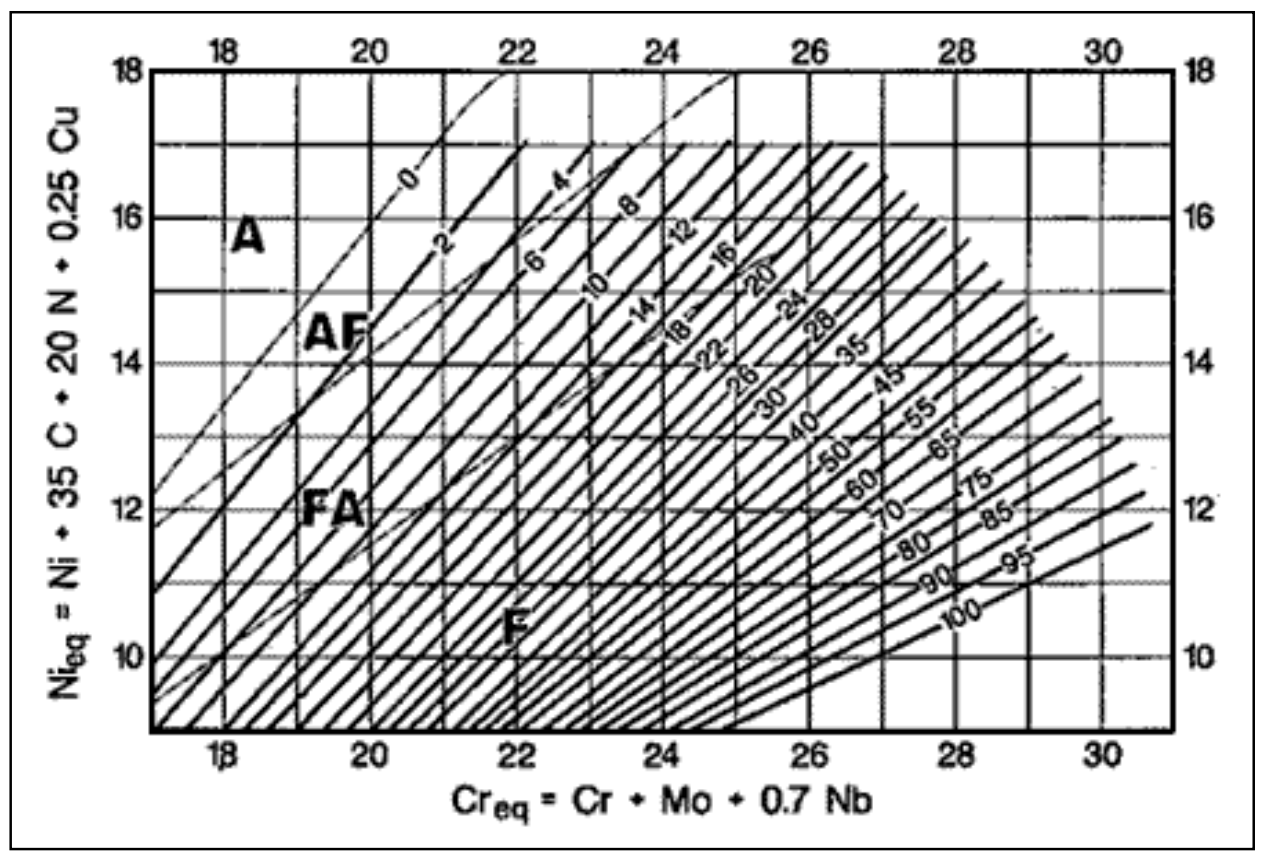

Fig. 5 WRC-1992 constitution diagram 
The main benefit for ferrite number has been its reproducibility, which welfares in standardization. Fabricated plate ferrite content can either be forecast by using constitution diagrams such as Schaeffler, DeLong and WRC or measured by using measuring instruments [20]. The WRC-1992 constitutional diagram is used in the present study and the same is presented in Figure 5. Feritscope measuring method was used for measuring real ferrite present. The top surface of sample fabricated was ground flat to allow the measurement of ferrite content. Afterwards the initial arrangement, ferrite amounts were measured using Feritscope. Six readings were taken in transverse and longitudinal directions as shown in Fig 4 and the normal value of the ferrite content was documented.

\subsection{Microstructural studies}

In the present investigation, AISI 316L austenitic stainless steel thin plate fabricated by deposition using welding over the carbon steel base plate is characterized with microstructural analysis. The dilution of the fabricated plate component metal entered in parent metal could be significantly affected due to the difference in melting temperature between the low carbon steel and stainless steel thin plate metal and this effect will impact the subsequent microstructure and chemical composition. This chemical composition will also be affected by the mode of solidification and the weld dilution of the fabricating metal. Therefore, microstructure studies were carried out across the various zones of the fabricated thin plate. Scanning Electron Microscopy (SEM) was used to expose microstructure at different zones such as base metal, fusion zone and deposited metal.

\section{Results and discussion}

This section presents the results of both chemical composition analysis as well as ferrite number analysis as stated in the sequence of previous chapter. Also, the microstructure of the interface between the base metal and deposited metal for the fabrication of component is reported. As the three axis welding manipulator is employed in the present study of WAAM fabrication, the produced component is visibly so fair and further, the quality natures are discussed [21]. The discussions are also included to support the obtained results.

\subsection{Results of chemical composition analysis}

It is observed that the chemical composition of the thin plate fabricated as presented in Table 2 is only negligibly varied comparing the original 316L metal and the same is depending might be on the weld dilution i.e. metal get into the base metal as penetration. This might be happened due to the intermixing of the parent base low carbon steel metal with the deposited 316L stainless steel metal during welding deposition [22]. It is quite interesting to note that carbon content is found in the fabricated metal too even with the presence of some weld dilution. This ensured the process of limiting the ferrite content within the needed level so that suitable sensitization level and adequate immunity could be experienced in the fabricated metal. The similar trend is renowned for manganese content also. It was also found that sample have some amount of nickel, chromium, molybdenum content too as that of the properties of stainless steel because much of intermixing of stainless steel with low carbon 
steel has not been significantly affected the composition actually. In fact the fabricated sample has carbon content around 0.05 , which is reasonably acceptable one.

Table 2 Chemical composition of fabricated sample

\begin{tabular}{|l|l|l|l|l|l|l|l|l|}
\hline \multirow{2}{*}{ Sample } & \multicolumn{8}{|c|}{ Elements \% } \\
\cline { 2 - 9 } & $\begin{array}{c}\text { Carbon } \\
\mathrm{C}\end{array}$ & $\begin{array}{c}\text { Silicon } \\
\mathrm{Si}\end{array}$ & $\begin{array}{c}\text { Manganese } \\
\mathrm{Mn}\end{array}$ & $\begin{array}{c}\text { Chromium } \\
\mathrm{Cr}\end{array}$ & $\begin{array}{c}\text { Nickel } \\
\mathrm{Ni}\end{array}$ & $\begin{array}{c}\text { Molybdenum } \\
\text { Mo }\end{array}$ & $\begin{array}{c}\text { Phosphorous } \\
\mathrm{P}\end{array}$ & $\begin{array}{c}\text { Sulphur } \\
\mathrm{S}\end{array}$ \\
\hline $\begin{array}{l}\text { Fabricated Thin } \\
\text { walled sample }\end{array}$ & 0.051 & 0.721 & 1.582 & 17.434 & 10.824 & 2.536 & 0.026 & 0.011 \\
\hline
\end{tabular}

It is decided to predict the chemical content in the sample because to ensure and compare the results obtained during measurement during composition analysis. The predicted composition of the stainless steel thin plate and the measured values are shown in Table 3. It is seemed to be perfect as predicted values and measured values of the chemical composition of sample are identical and faithfully arranged to each other that apparent a fruitful measurement of the composition.

Table 3 Comparison of predicted and measured values of composition

\begin{tabular}{|c|c|c|c|c|c|c|c|c|c|c|c|c|c|c|c|c|}
\hline \multirow{2}{*}{ Samples } & \multicolumn{2}{|c|}{$\mathrm{C}$} & \multicolumn{2}{|c|}{$\mathrm{Si}$} & \multicolumn{2}{|c|}{$\mathrm{Mn}$} & \multicolumn{2}{|c|}{$\mathrm{Cr}$} & \multicolumn{2}{|c|}{$\mathrm{Ni}$} & \multicolumn{2}{|c|}{ Mo } & \multicolumn{2}{|c|}{$P$} & \multicolumn{2}{|c|}{$S$} \\
\hline & $\mathrm{P}$ & $\mathrm{O}$ & $\mathrm{P}$ & $\mathrm{O}$ & $\mathrm{P}$ & $\mathrm{O}$ & $\mathrm{P}$ & $\mathrm{O}$ & $\mathrm{P}$ & $\mathrm{O}$ & $\mathrm{P}$ & $\mathrm{O}$ & $\mathrm{P}$ & $\mathrm{O}$ & $\mathrm{P}$ & $\mathrm{O}$ \\
\hline $\begin{array}{c}\text { Fabricated } \\
\text { thin } \\
\text { plate }\end{array}$ & 0.057 & 0.051 & 0.619 & 0.721 & 1.468 & 1.582 & 16.198 & 17.434 & 10.699 & 910.8242 & 2.411 & 2.536 & 60.006 & 0.026 & 0.006 & 0.011 \\
\hline
\end{tabular}

P-Predicted; O-Observed

\subsection{Results of ferrite measurement}

It is decided to predict the ferrite content in the sample also along with measurement using Ferritscope. The nickel and chromium equivalent values were observed from the WRC-1992 diagram followed for stainless steels to predict the ferrite number. These equivalents were employed to decide FN from the WRC-1992 diagram. From the Table 4, it is found that FN presence is damn sure and this effect due to the reason that the parent low carbon steel has no chromium, nickel and has high carbon as associated to the austenitic stainless steel.Further, it is apparent that both predicted Ferrite Number (FN) values acquired from the WRC-1998 diagram and measured ferrite content values using ferritescope shows a very good agreement. Especially while looking at the chromium equivalent and nickel equivalent, those values were very close to standard stainless steels. It is typically acceptable if the predicted FN and measured FN values differed between from 4 to 8 [23]. But, it is so noteworthy that the difference between predicted and measured $\mathrm{FN}$ in the present study are capable and satisfactorily acceptable. 
Table 4 Comparison of predicted and measured values of FN

\subsection{Microstructure of weld interface}

\begin{tabular}{|l|l|l|l|l|}
\hline Sample & WCE & WNE & $\begin{array}{l}\text { Predicted } \\
\text { FN }\end{array}$ & $\begin{array}{l}\text { Measured } \\
\text { FN }\end{array}$ \\
\hline $\begin{array}{c}\text { Fabricated } \\
\text { 316L thin } \\
\text { plate }\end{array}$ & 19.97 & 11.02 & 11 & 5.68 \\
\hline
\end{tabular}

Figure 6 depicts the interface of stainless steel thin plate component and low carbon parent metal. It is understood that there is no indication of destructive visible defects in the fabricated thin plate sample. It is evident that the substantial ferrite presence in the stainless steel component supports for the good strength as in the case of stainless steel as well and for providing enough corrosion resistance properties. The microstructure of deposited 316L for building the thin plate exhibits the presence of very low amount of carbon so that smaller pits, digs, pores and spongy like structures whereas the clear surface which indicates the maximum corrosion resistance surface [24]. Thus, SEM images revealed that the austenite stainless steel cladded specimen obtained at optimum condition was found to be acceptable and soundness exhibits the better corrosion resistance.

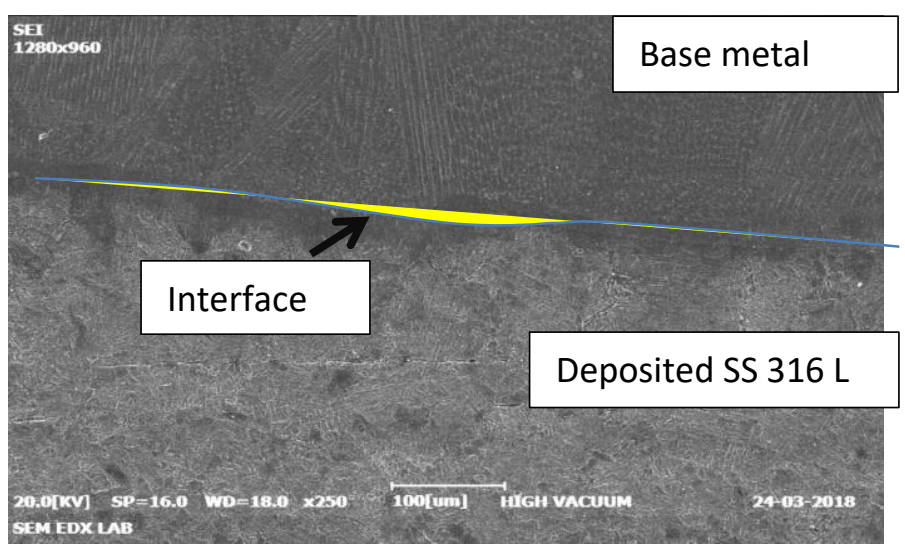

Fig. 6 Microstructure of interface

\section{Conclusions}

The present study has been successfully carried out for the fabrication of thin walled plate structure using a typical WAAM. The following conclusions are arrived from the present study carried out to fabricate a thin walled plate component based on the concept close to WAAM,

$>$ Chemical compositions of all elements are found to be almost same in both the cases of metal joining by welding process as well as metal component fabrication by welding process.

$>$ Constitution diagram shall also be used for the prediction of FN even while using WAAM components fabrication

Measured presence of ferrite is around 5.68 FN is greatly evident for the good quality of fabricated thin walled plate. 
Microstructure of the interface between low carbon steel and stainless steel indicates no defects rose during fabrication.

- There is a close agreement between the predicted FN and measured FN indicates the suitability of WAAM for metal component fabrication to withstand the corrosion.

\section{Acknowledgements}

Authors would like to highly acknowledge the supports from National Institute of Technology, Tiruchirappalli and Coimbatore Institute of Engineering and Technology, Coimbatore in conducting this work successfully.

\section{References}

1. Sowrirajan, M., P. Koshy Mathews, and S. Vijayan. "Simultaneous multi-objective optimization of stainless steel clad layer on pressure vessels using genetic algorithm." Journal of Mechanical Science and Technology 32.6 (2018): 2559-2568.

2. Sowrirajan, M., S. Vijayan, and M. Arulraj. "Application of Regression Models in MultiObjective Optimization of FCAW Process Variables on Volume of Austenitic Stainless-Steel Clad Layers." JOURNAL OF THE CHINESE SOCIETY OF MECHANICAL ENGINEERS 42.2 (2021): 227-234.

3. M. Sowrirajan, P. Koshy Mathews, S. Vijayan, Y. Amaladasan, "Effect of weld dilution on post-weld thermal conductivity of austenitic stainless steel clad layers", Materials Research Express, 5 (2018) 096512.

4. P. K. Palani, N. Murugan, "Optimization of weld bead geometry for stainless steel claddings deposited by FCAW", J. Mater. Process. Technol., 190 (2007) 291-299.

5. Sowrirajan, Maruthasalam, P. Koshy Mathews, and S. Vijayan, "Investigation and optimization of process variables on clad angle in 316L stainless steel cladding using genetic algorithm." High Temperature Material Processes: An International Quarterly of HighTechnology Plasma Processes, 21.2 (2017).

6. N. Murugan, R. S. Parmar, "Effect of welding conditions on microstructure and properties of type 316L stainless steel submerged arc cladding”, Weld. J., 76 (1997) 210-220.

7. R. A. Rahman Rashid, S. Abaspour, S. Palanisamy, N. Matthews, M. S. Dargusch, "Metallurgical and geometrical characterisation of the 316L stainless steel clad deposited on a mild steel substrate”, Surf. Coat. Technol., 327 (2017) 174-184.

8. Pritesh Prajapati, Vishvesh J. Badheka, "Investigation on various welding consumables on properties of carbon steel material in gas metal arc welding under constant voltage mode", Sadhana., 42 (2017) 1751-1761.

9. S. Ragu Nathan, V. Balasubramanian, S. Malarvizhi, A. G. Rao, "Effect of welding processes on mechanical and microstructural characteristics of high strength low alloy naval grade steel joints", Defence Technology, 11 (2015) 308-317.

10. Peng Xu, ChengXin Lin, ChaoYu Zhou, XinPeng Yi, "Wear and corrosion resistance of laser cladding AISI 304 stainless steel/Al $\mathrm{O}_{3}$ composite coatings”, Surf. Coat. Technol., 238 (2014) 9-14.

11. G. Benghalia, J. Wood, "Material and residual stress considerations associated with the autofrettage of weld clad components”, Int. J. Pressure Vessels. Piping., 139 (2016) 146-158. 
12. P. Sathiya, P. M. Ajith, R. Soundararajan, "Genetic algorithm based optimization of the process parameters for gas metal arc welding of AISI 904L stainless steel”, J. Mater. Sci. Technol., 27 (2013) 2457-2465.

13. F. H. Ley, S. W. Campbell, A. M. Galloway, N. A. McPherson, "Effect of shielding gas parameters on weld metal thermal properties in gas metal arc welding”, Int. J. Adv. Manuf. Technol., 80 (2015) 1213-1221.

14. Bin Wu, Bin Wang, Xieting Zhao, Huan Peng, "Effect of active fluxes on thermo-physical properties of 309L stainless-steel welds", J. Mater. Process. Technol., 225 (2018) 212-218.

15. Arulraj, M., P. K. Palani, and M. Sowrirajan. "Optimization of squeeze casting parameters of hybrid aluminium matrix composite using Taguchi approach." Proceedings of the Institution of Mechanical Engineers, Part E: Journal of Process Mechanical Engineering (2021): 0954408921989864.

16. Y. A. Cengel, "Introduction to Thermodynamics and Heat Transfer", Second Edition, The McGraw-Hill companies, (2008).

17. Siva K, Murugan N, Raghupathy VP, "Modelling, analysis and optimisation of weld bead parameters of nickel based overlay deposited by plasma transferred arc surfacing”, Archives of Computational Materials Science and Surface Engineering, 2009, 1(3):174-82

18. Pilar De Tiedra, Oscar Martin, "Effect of welding on the stress corrosion cracking behaviour of prior cold worked AISI 316L stainless steel studied by using the slow strain rate test”, Mater. Des., 49 (2013) 103-109.

19. https://pec.engr.wisc.edu/Assets/Machines/LFA/LFA447_Brochure.pdf

20. W. J. Parker, R. J. Jenkins, C. P. Butler, G. L. Abbott, "Flash method of determining thermal diffusivity, heat capacity, and thermal conductivity", J. Applied physics., 32 (1961) 16791684.

21. Mahesh Kumar Yadav, Sachin K. Singh, Ahsen Parwez, Sameer Khandekar, "Inverse models for transient wall heat flux estimation based on single and multi-point temperature measurements", Int. J. Therm. Sci., 124 (2018) 307-317. 